\title{
Internacionalização e transnacionalização da educação superior no programa Ciência sem Fronteiras: amálgamas e contradições
}

\author{
Internationalization and transnationalization of higher \\ education in Science Without Borders Program: \\ amalgams and contradictions
}

Maria das Graças Martins da SILVA'

Joíra Aparecida Leite de Oliveira Amorim MARTINS²

\begin{abstract}
Resumo
O texto analisa a concepçáo e a implementação do Programa Ciência sem Fronteiras (CsF), estabelecendo relação com ideias norteadoras sobre internacionalização e transnacionalização da educação superior. Do ponto de vista metodológico, vale-se da pesquisa documental e bibliográfica. Adota-se a ideia de internacionalizaçâo da educação superior como troca mútua e solidária no campo acadêmico; de outra parte, entende-se que a transnacionalizaçáo expressa a agenda do mercado e do privado. A partir dos dados, conclui-se que o CsF é anunciado como um processo de internacionalização da educação superior no Brasil, porém, o seu funcionamento revela características da transnacionalização.
\end{abstract}

Palavras-chave: Internacionalização. Transnacionalização. Educação Superior.
Abstract

The paper examines the conception and implementation of the Science without Borders Program (SwB), establishing relationship with guiding ideas about internationalization and transnationalization of higher education. From a methodological point of view, this paper is documented and bibliographical research. The text adopts the idea of internationalization of higher education as mutual exchange and solidarity in the academic field; while on the other hand, understanding that transnationalization is supported by the private sector. From the data presented, it is concluded that $\mathrm{SwB}$ is advertised as a process of internationalization of higher education in Brazil, however, its operation reveals characteristics of the transnationalization.

Keywords: Internationalization .Transnationalization. Higher Education.

1 Pós-doutora em Educaçáo, professora associada da Universidade Federal de Mato Grosso. Membro do Grupo de Estudos e Pesquisa em Políticas Educacionais (GEPDES). Avenida Fernando Correa, n.2367, Boa Esperança. Cuiabá. MT. CEP: 78060-900. Tel.: (65) 3615-8431. Email:<gracams2@hotmail.com>.

2 Mestre em Educação, técnica-administrativa da Universidade Federal de Mato Grosso. Membro do Grupo de Estudos e Pesquisa em Políticas Educacionais (GEPDES). Avenida Fernando Correa, n.2367, Boa Esperança. Cuiabá. MT. CEP: 78060-900. Tel.: (65) 3313-7294. Email:<joira.martins@gmail.com>.

R. Educ. Públ.

Cuiabá

v. 27

n. 64

p. $111-131$ jan./abr. 2018 


\section{Introdução}

Os estudos mostram que desde a Antiguidade ocorria troca de informaçáo entre povos. Na Idade Média, por sua vez, a mobilidade internacional se apresentava pela busca de estudos universitários, como explicam Charle e Verger (1996, p. 49): "As populaçóes universitárias medievais eram bastante móveis, uma vez que, em tese, nenhuma fronteira se opunha à circulação dos homens nem à validade dos diplomas." Lembram os autores que a circulação com vistas aos estudos universitários proporcionava, igualmente, uma experiência existencial, um tipo de sociabilidade, uma iniciaçáo educativa que era valorizada pelos povos.

No presente, o tema da mobilidade ou internacionalização ganha notoriedade, agregando características novas, como o interesse do Estado e do setor de mercado. A tendência se intensifica largamente após a Terceira Revolução Industrial, também identificada como Revolução Digital ou Revolução Técnico-Científica Informacional $^{3}$, o que é examinado por Dias Sobrinho (2005, p. 139):

A modernização dos meios de transporte e diversos programas de financiamento e estratégias de organização de eventos e variados trabalhos de cooperaçáo facilitam muito a circulação de professores e estudantes. A cooperaçáo acadêmica pode ser altamente potencializada hoje em dia pela interconexão das instituiçôes e de grupos de pesquisadores, ou seja, pela constituição de redes mundiais permitindo o acesso imediato a informaçóes longínquas, unindo o local ao global. (DIAS SOBRINHO, 2005, p. 139).

Vive-se, pois, um tempo de interação entre países, sobretudo, levando em conta aspectos econômicos, sociais, culturais, tecnológicos e políticos. Nessa seara, a universidade participa com intensidade crescente, desenvolvendo atividades de ensino e pesquisa, além de outras formas de intercâmbio.

Tal dinâmica tem levado ao debate da internacionalização e da transnacionalização da educação superior, que busca interpretar esses movimentos, considerados opostos em termos de princípios e práticas.

3 A citada revoluçáo inicia em meados do século XX e corresponde ao processo de inovaçốes no campo da informática e suas aplicaçôes nos campos da produçâo e do consumo. As grandes realizaçôes desse período são o desenvolvimento da chamada química fina, a biotecnologia, a escalada espacial, a robótica, a genética, entre outros importantes avanços (PENA, 2015). 
Nessa linha, o presente texto visa analisar aspectos essenciais da concepção e implementação do Programa Ciência sem Fronteiras (CsF), estabelecendo relação com as ideias norteadoras sobre internacionalização e transnacionalização da educação superior. Do ponto de vista metodológico, vale-se da pesquisa documental e bibliográfica, traduzida pelo exame da legislação, de documentos internacionais e da literatura acadêmica.

\section{Internacionalização e transnacionalização: ideias e (em) movimentos}

A internacionalização na educação superior articula-se à tradição da instituição universitária como contributo acadêmico mútuo, cuja perspectiva é explicada por Dias Sobrinho (2005, p. 139):

Por vocação e tradição, a universidade tem sido uma instituição que preserva e alimenta a dimensão internacional, seja pelo sentido da ciência e pelos critérios de qualidade e cientificidade, isto é, pelos valores autenticamente acadêmicos, seja pelas iniciativas práticas de intercâmbio institucionais e mobilidade de estudantes e professores. [...] O sentido predominante da internacionalização universitária tem sido ao longo dos tempos o de colaboraçáo acadêmica buscando o avanço da ciência e da educação. (DIAS SOBRINHO, 2005, p. 139).

Nessa via, a internacionalização da educação superior pode contribuir para desenvolver habilidades interculturais, ampliaçâo das vertentes do conhecimento acadêmico, visão holística do saber e larga vivência pessoal com objetivo de solidariedade mútua, maior tolerância entre povos e cooperação mundial. Tal prática, tradicionalmente, pautou-se nos princípios da solidariedade e da reciprocidade, tendo como objetivo o diálogo, fundado no respeito ao diferente e na troca de conhecimentos segundo um interesse humanitário.

Contudo, políticas globais situadas em período relativamente recente têm afetado as políticas de educaçáo superior, tendendo a tratar a educaçáo como mercadoria, o que gera pressão para que as exigências do setor produtivo se sobreponham aos ideais da cooperação internacional solidária. Sendo assim, as instituiçóes de educação superior sofrem os efeitos de tais forças, inclinando-se a uma visão mais pragmática, competitiva, utilitarista e produtora (ou indutora) de inovaçôes mercadológica. 
Tal realidade insere-se no que Harvey (1989) interpreta como condicionantes do sistema capitalista, que, sob a acumulação flexível, promovem a produção e a veiculaçáo do conhecimento científico e técnico na direção de interesses voltados à reprodução e expansão desse sistema. Como explica Harvey (1989, p. 151): "O próprio saber se torna uma mercadoria-chave, a ser produzida e vendida a quem pagar mais, sob condiçôes que são elas mesmas cada vez mais organizadas em base competitivas."

De fato, a identificação da educação como um bem público sofre um revés na década de 1990. A esse propósito, Dias (2002) mostra as forças atuantes na Conferência Mundial sobre Educação Superior (1998), protagonistas da defesa da natureza pública da educação e, de forma ambígua, também da sua comercialização:

Em 1998, em Paris, durante a Conferência Mundial sobre Educação Superior (CMES) na UNESCO, a comunidade acadêmica internacional e governos de mais de 180 países manifestaram, de maneira clara e insofismável, sua decisão de manter o ensino superior como um direito e um bem público. No entanto, ao mesmo tempo e sem fazer alarde, o secretariado da OMC, com o apoio de representantes de alguns governos que contraditoriamente aprovaram a Declaração de Paris, manobrava para criar normas que tratassem o ensino superior como uma mercadoria a ser comercializada e liberalizada, retirando dos Estados nacionais, em termos práticos, o direito de decidir com soberania sobre açôes que visem formar cidadãos conscientes e responsáveis. (DIAS, 2002, p. 33, grifos nossos).

A citada Organização Mundial do Comércio (OMC) possui como regra geral para todo serviço comercial o Acordo Geral sobre o Comércio de Serviços (AGCS), ou seja: "O objetivo do AGCS, aprovado em abril de 1994, é o de provocar uma liberalização progressiva dos serviços, inclusive os educacionais" (DIAS, 2002, p. 48). A partir de 1999, em documento da área de cobertura do AGCS, a educação passa a ser regulamentada como serviço, o que é aceito pelos países membros, incluindo o Brasil ${ }^{4}$. Tal aceitaçáo se consubstanciaria por acordos bi ou multilaterais entre eles.

4 O Brasil, apesar de aceitar a inclusão da educação como serviços pela AGCS, ainda não formalizou acordo específico sobre o assunto, embora medidas caminhem nessa direção, a exemplo da autorização dada, em 14 de maio de 2014, pelo Conselho Administrativo de Defesa Econômica/Ministério da Justiça, com vistas à fusão das empresas de ensino superior Anhanguera e Kroton, tornando-a "[...] a maior companhia de ensino superior do mundo com mais de um milhão de alunos" (CADE autoriza união de Anhanguera e Kroton, com ressalvas, 2015, não paginado). 
A condição de educação como mercadoria, naturalmente, presume modalidades transnacionais de aplicação de serviços universitários mercantis. Santos (2011) detalha algumas dessas possibilidades:

A oferta transfronteiriça consiste na provisão transnacional do serviço sem que haja movimento físico do consumidor. [...] $\mathrm{O}$ consumo no estrangeiro consiste na provisão do serviço através do movimento transnacional do consumidor. [...] a presença comercial e consiste em produtor privado de educação superior estabelecer sucursais no estrangeiro a fim de aí vender os seus serviços. [...] a presença de pessoas consiste na deslocação temporária ao estrangeiro de fornecedores de serviços sediados num dado país, sejam eles professores ou pesquisadores. (SANTOS, 2011, p. 34-35).

As formas de mercadorizar a educação superior, portanto, rapidamente diversificam-se e adquirem vigor. No caso brasileiro, a título de exemplo, Carvalho (2013, p. 773$)$ trata o movimento em curso como "[...] multifacetado de financeirização, oligopolização e internacionalização da educação superior brasileira." Explica a autora que: "A manifestação mais significativa do fenômeno de mercantilização pode ser observada por meio das aquisições realizadas por fundos privateequity e pela abertura de capital das empresas educacionais na bolsa de valores (IPOs) a partir de 2007" (CARVALHO, 2013, p. 770).

Assim, pois, sob o eixo da transnacionalização, há claros sinais de que a educação superior está na linha de frente de um processo mercadológico sem fronteiras, movimento agressivo na sua disseminação, mas que não se processa sem contradiçóes.

\section{A internacionalização na política da educação superior no Brasil}

A internacionalização da educação superior, do ponto de vista institucional, configura-se com a criação do Conselho Nacional de Desenvolvimento Científico e Tecnológico (CNPq) e da Campanha Nacional de Aperfeiçoamento de Pessoal de Nível Superior (atual Capes - Coordenação de Aperfeiçoamento de Pessoal de Nível Superior), em 1951. Ambos foram criados com o objetivo de atender a necessidade de formaçáo de especialistas e pesquisadores para o entáo projeto de desenvolvimento do país (MOROSINI, 2008).

No marco vigente, segundo a Constituição Federal de 1988 (CF), pode-se cogitar em seu preâmbulo o sentido humanista e de civilidade nas relações internacionais: 
Nós, representantes do povo brasileiro, reunidos em Assembleia Nacional Constituinte para instituir um Estado Democrático, destinado a assegurar o exercício dos direitos sociais e individuais, a liberdade, a segurança, o bem-estar, o desenvolvimento, a igualdade e a justiça como valores supremos de uma sociedade fraterna, pluralista e sem preconceitos, fundada na harmonia social e comprometida, na ordem interna e internacional, com a solução pacífica das controvérsias [...] (BRASIL, 1988, grifos nossos).

Tal qual a CF, a Lei de Diretrizes e Bases da Educação Nacional (LDB), Lei no 9.394/96, de 20 de dezembro de 1996, não registra explicitamente sobre a política de internacionalização da educação brasileira. Porém, por suas diretrizes é possível interpretar que a cooperação internacional possui relevância, algo a ser alcançado pelas universidades, associando-a à atividade de ensino, pesquisa e extensão, visando contribuir para o desenvolvimento do país e para a redução dos desequilíbrios regionais.

No Plano Nacional de Educação 2011-2014, aprovado pela Lei n. ${ }^{\circ}$ 13.005, de 25 de junhode 2014, com vigência de 2014 a 2024, ganham destaques açóes de internacionalização da educação superior na pesquisa e na pós-graduação, segundo o objetivo de aumentar qualitativa e quantitativamente o desempenho científico e tecnológico do país. Na comparação entre o atual PNE e o PNE anterior, vale ressaltar que no campo da internacionalização da educação superior é alterado o termo diretrizes para estratégias, o que sugere açôes pragmáticas e em curto prazo. Nessa toada, parece inserir-se o Programa CsF, criado em 2011, pouco antes da aprovação do PNE 2011-2014.

\section{Ciências sem Fronteiras: criação e implementação}

$\mathrm{O} \mathrm{CsF}$ configura o primeiro programa que trata com exclusividade de açóes da internacionalização brasileira vinculadas à educação superior, no sentido de enviar estudantes brasileiros de nível de graduação ao exterior. O Programa foi criado pelo Decreto n. ${ }^{\circ}$ 7.642, de 13 de dezembro de 2011, financiado pelas agências de fomento CAPES e CNPq, de acordo com o objetivo principal de:

[...] propiciar a formação e capacitaçáo de pessoas com elevada qualificação em universidades, instituiçóes de educaçáo profissional e tecnológica, e centros de pesquisa 
estrangeiros de excelência, além de atrair para o Brasil jovens talentos e pesquisadores estrangeiros de elevada qualificação, em áreas de conhecimento definidas como prioritárias. (BRASIL, 2011h).

Desde o seu anúncio percebe-se um discurso ufanista, a exemplo do realizado pela Presidente Dilma Rousseff na cerimônia de regulamentação, em 13 de dezembro de 2011:

Nós somos, de fato, um país muito rico. Nós temos petróleo, nós temos minério [...]. Nós temos também uma agricultura bastante competitiva e produtiva, nós temos uma indústria. Mas, o que nós temos certeza que vamos precisar, nos próximos anos, é de homens e mulheres muito bem preparados, muito bem capacitados e que tenham condiçōes de permitir que o nosso país adentre à economia do conhecimento, sendo capaz de produzir ciência, de inovar e de absorver tecnologia e transformar. (BRASIL, 2011i).

A par do apelo à economia do conhecimento, o CsF aparenta vir para materializá-la. Não por acaso, seu surgimento é assim descrito por Catani e Silva Júnior (2013):

Em 25 de janeiro de 2011, o presidente Barack Obama anunciou, em discurso do Estado, a importância da relação bilateral Brasil- Estados Unidos. Visitou Brasília e Rio de Janeiro (março de 2011), quando se encontrou com a presidente Dilma Rouseff. Foi nessa visita que o Programa CsF foi comentado como uma área estratégica de desenvolvimento (Entrevista concedida pelo professor William L. Gertz, do American Institute For Foreing Study, ao professor Joáo dos Reis Silva Júnior na cidade de Nova York em 12 de julho de 2012). (CATANI; SILVA JÚNIOR, 2013, p. 171).

O primeiro anúncio sobre o Programa foi feito pelo Ministro da Ciência e Tecnologia e Inovação (MCTi), Aloisio Mercadante, na 38 a reunião do Conselho de Desenvolvimento Econômico e Social (CDES), em julho de 2011, em Brasília. $\mathrm{Na}$ ocasião, Mercadante destacou que o Brasil é o $13^{\circ}$ no ranking de produçáo científica mundial, média cinco vezes maior que a do restante das outras naçóes; ainda assim, ele acredita que o país precisa produzir mais patentes e o CsF vai nessa direção. A seu ver: "[...] os melhores estudantes do Brasil, nas melhores 
universidades do mundo. Assim poderemos superar o maior desafio do país e dar um salto quântico na formação para áreas estratégicas de forma sustentável, ampliando os setores de média e alta tecnologia" (CsF, 2011f).

Como se nota, o CsF nasce com o propósito de estimular o avanço da ciência nacional em tecnologia, inovação e competitividade, por meio da expansão da mobilidade internacional, utilizando-se como estratégia o incentivo financeiro para aumentar a presença de pesquisadores e estudantes brasileiros em instituiçóes de excelência (expressão utilizada no documento de criação do Programa Decreto n. ${ }^{\circ}$ 7.642/2011) no exterior e para atrair jovens talentos científicos e investigadores para trabalhar no Brasil.

O Programa desenvolve-se de acordo com duas modalidades principais: formação e capacitação de pessoas com elevada qualificação em universidades, instituiçóes de educação profissional e tecnológica e centros de pesquisa estrangeiros de excelência; e atração de jovens talentos, principalmente brasileiros, e pesquisadores renomados estrangeiros para vir ao Brasil desenvolver projetos de pesquisa por cooperação científica e tecnológica. Ambas se vinculam ao financiamento de bolsas e fomento à pesquisa.

A primeira modalidade possui como público-alvo: a) estudantes de graduação na modalidade graduação-sanduíche; b) estudantes de doutorado na modalidade doutorado-sanduíche; c) candidatos graduados ou mestres à formação plena de doutoramento na modalidade doutorado pleno; d) e candidatos doutores na modalidade pós-doutorado e docentes, pesquisadores e estudantes de cursos técnicos e superiores oferecidos por institutos de formação profissional e tecnológica na modalidade educação profissional e tecnológica.

A segunda modalidade citada possui como público-alvo: a) jovens cientistas de talento, principalmente brasileiros com destacada produção científica ou tecnológica na modalidade jovens talentos; b) e lideranças internacionais, estrangeiros ou brasileiros, com expressiva atuação no exterior na modalidade pesquisadores visitantes estrangeiros.

Na ocasiáo do primeiro anúncio do Programa (julho de 2011), foi publicado em meios de comunicação que o CNPq concederia 35 mil bolsas e a CAPES o montante de $40 \mathrm{mil}$ bolsas, totalizando $75 \mathrm{mil}$ bolsas, com investimento governamental inicial de 3 bilhóes de reais e 160 milhóes de reais. Ressalte-se que o governo esperava que o investimento crescesse por meio da iniciativa privada, que arcaria com mais 25 mil bolsas, possibilitando garantir 100 mil bolsas até os anos de 2014/2015.

Foi instituído pela Portaria Interministerial n. 1, do Ministério da Educação, em 9 jan. 2013, que as áreas e temas prioritários de atuação do Programa vinculamse à ciência, tecnologia e inovação, definidas pela avaliação ou interesse do governo 
federal, compreendendo Engenharias e demais áreas tecnológicas; Ciências Exatas e da Terra; Biologia, Ciências Biomédicas e da Saúde; Computação e Tecnologias da Informação, entre outras áreas do conhecimento.

A pesquisa ora apresentada enfatiza a primeira modalidade do Programa CsF, a que trata da formação e capacitaçâo de pessoas com elevada qualificação em universidades, instituiçóes de educação profissional e tecnológica, e centros de pesquisa estrangeiros de excelência, no recorte do público-alvo constituido de estudantes de graduaçáo-sanduíche, de acordo com o realizado entre agosto de 2011 a agosto de 2014.

Para uma compreensão do CsF, o Quadro 1 sistematiza eventos marcantes, considerando o período estudado. Assim:

Quadro 1 - Programa Ciência sem Fronteiras. Eventos marcantes - agosto de 2011 a agosto de 2014

\begin{tabular}{|c|c|}
\hline Data & Descrição \\
\hline Agosto de 2011 & $\begin{array}{l}1^{\text {a }} \text { convocação para o Programa CSF, mediante a Chamada Pública CAPES } \\
\text { n. } .^{\circ} 01 / 2011 \text {, com destino para as Universidade dos EUA. }\end{array}$ \\
\hline Setembro de 2011 & $\begin{array}{l}\text { O CNPq (Conselho Nacional de Desenvolvimento Científico e Tecnológico) } \\
\text { entrou em contato com os Coordenadores do Programa de Iniciação } \\
\text { Científica e Tecnológica (PIBIC/PIBIT) das Universidades brasileiras para } \\
\text { apresentar o Programa CsF e explicar que cada Universidade receberia } \\
\text { uma quota de vagas para contemplar estudantes bolsistas e ex-bolsistas } \\
\text { dos Programas de Iniciação Científica. }\end{array}$ \\
\hline $\begin{array}{l}\text { Agosto a Dezembro } \\
\text { de } 2011\end{array}$ & $\begin{array}{l}\text { Período marcado por recorrentes desencontros de informações entre } \\
\text { os órgãos fomentadores, as Universidades brasileiras e os candidatos, } \\
\text { principalmente a respeito da definição dos cursos elegíveis. }\end{array}$ \\
\hline $13 / 12 / 2011$ & $\begin{array}{l}\text { Publicação do Decreto n. }{ }^{\circ} 7.642 \text { da Presidência da República, que instituiu } \\
\text { oficialmente o Programa CSF, sendo detalhada a forma de gestão, } \\
\text { divulgação e fomento. }\end{array}$ \\
\hline Dezembro de 2011 & $\begin{array}{l}2^{a} \text { convocação para o Programa CsF, mediante as Chamadas Públicas } 102 \\
\text { até } 106 .\end{array}$ \\
\hline Março de 2012 & $\begin{array}{l}3^{a} \text { convocação para o Programa CsF, por meio das Chamadas Públicas de } \\
108 \text { até } 116 .\end{array}$ \\
\hline Agosto de 2012 & $\begin{array}{l}4^{a} \text { convocação para o Programa CsF, por meio das Chamadas Públicas de } \\
117 \text { até } 124 \text {. }\end{array}$ \\
\hline Novembro de 2012 & 5a convocação para o Programa CsF, das Chamadas Públicas de 126 até 134. \\
\hline
\end{tabular}




\begin{tabular}{|c|c|}
\hline Data & Descrição \\
\hline $18 / 12 / 2012$ & $\begin{array}{l}\text { Publicação da Portaria Interministerial n.1466, do Ministério da Educação, } \\
\text { que intuiu oficialmente o Programa Inglês sem Fronteiras (IsF). }\end{array}$ \\
\hline 09/01/2013 & $\begin{array}{l}\text { Publicação da Portaria Interministerial n.1, do Ministério da Educação, } \\
\text { que definiu definitivamente as áreas e temas prioritários de atuação do } \\
\text { Programa CsF. }\end{array}$ \\
\hline Fevereiro de 2013 & $\begin{array}{l}\text { 6a convocação para o Programa CsF, por meio das Chamadas Públicas } 136 \\
\text { até } 142 .\end{array}$ \\
\hline $24 / 04 / 2013$ & $\begin{array}{l}\text { Veto do Ministério de Educação brasileiro da Chamada Pública n. }{ }^{\circ} \\
127 \text { com destino às Universidades de Portugal, justificado pelo fato da } \\
\text { elevada procura por Portugal, em detrimento dos países de outra língua, } \\
\text { considerando que o Programa possui como um dos objetivos principais } \\
\text { incentivar a proficiência em uma segunda língua. }\end{array}$ \\
\hline Maio de 2013 & $\begin{array}{l}7^{\text {a }} \text { convocação para o Programa CsF, por meio das Chamadas Públicas de } \\
143 \text { até } 155 \text {. }\end{array}$ \\
\hline Outubro de 2013 & $\begin{array}{l}8^{a} \text { convocação para o Programa CsF, por meio das Chamadas Públicas de } \\
156 \text { até } 174 \text {. }\end{array}$ \\
\hline Agosto de 2014 & $\begin{array}{l}\text { 9a convocação para Programa CsF por meio das Chamadas Públicas de } \\
179 \text { até } 204 .\end{array}$ \\
\hline
\end{tabular}

Fonte: Organizado pelas autoras, segundo documentos do Programa CsF.

Ao longo do período examinado, observa-se que o Programa se constrói apressadamente, em meio a desencontros de informaçóes e divulgação de atos oficiais posteriores à implementaçấo de açôes a eles relacionadas.

Cabe destacar, de acordo com o registro das Chamadas Públicas, os seguintes países onde se destinam os estudantes brasileiros de graduação: Canadá, EUA, Bélgica, Austrália, Alemanha, Reino Unido, Coréia do Sul, França, Itália, Espanha, Holanda, Hungria, Japão, Finlândia, Suécia, Noruega, China, Irlanda, Áustria, Nova Zelândia, Portugal e Polônia. Desses, o Canadá predominou, totalizando sua participação em 12 Chamadas Públicas, seguindo-se os Estados Unidos da América, com nove. Não por acaso, são países onde se localizam instituições de ensino superior que aparecem com frequência em posiçóes de frente em rankings ${ }^{5}$

5 A título de exemplo acerca dos rankings internacionais: The World Reputations Rankings (<http://www. timeshighereducation.co.k/world-university-rankings/2014/reputation-ranking> e QS World University Rankings (<http://www.topuniversities.com/university-rankings/world-university-rankings/2013\#sorting $=$ rank + region $=+$ country $=+$ faculty $=+$ stars $=$ false + search $=>$ ). 
internacionais, o que, inclusive, pode representar uma intencionalidade da política educacional brasileira em aliar-se à lógica competitiva inerente a esse processo.

No entanto, dentre as Instituiçóes de Ensino Superior (IES) receptoras dos estudantes, algumas não figuram em institutos de classificação, o que parece contradizer a intenção de "[...] formação e capacitação de pessoas com elevada qualificação em universidades, instituiçôes de educação profissional e tecnológica, e centros de pesquisa estrangeiros de excelência" (BRASIL, 2011h). Nesse sentido, a título de exemplo: a Chamada Pública n. ${ }^{\circ} 132$ anunciou a destinação dos bolsistas para as Universidades e Instituiçóes Comunitárias Historicamente Negras dos EUA, bem como uma lista de 31 instituiçóes contempladas. Segundo levantamento realizado pelas pesquisadoras em março de 2014, no site de rankings The World Reputations Rankings e QS World University Rankings, nenhuma se classifica como melhores do mundo.

Mais adiante, percebe-se um afrouxamento com relação à posição das IES de destino, conforme divulgado no site oficial do Programa CsF, subitem Instituições de Destino, acessado em 29 set. 14:

Os estudantes e pesquisadores do Ciência sem Fronteiras terão o seu treinamento nas melhores instituiçóes e grupos de pesquisa disponiveis, prioritariamente entre os mais bem conceituados para cada grande área do conhecimento de acordo com os principais rankings internacionais (CsF, 2011e, grifo nosso).

Há de pontuar que a lógica de rankiamento de instituiçóes de ensino superior suscita questionamentos, sobretudo tendo em mira critérios definidos pelas agências para a escolha das supostamente melhores. Por isso, a sua abordagem apenas se justifica pela evidência atribuída à questáo pelos gestores do Programa CsF.

Para melhor discernimento do CsF, no que segue, são apresentadas as principais alteraçóes ocorridas ao longo das convocaçóes públicas, na modalidade de bolsas de graduaçáo-sanduíche, divulgadas no período de 2011 a agosto de 2014.

A primeira grande alteração incidiu sobre a sua execução. Ou seja: antes da sua instituição oficial (de agosto a dezembro de 2011), o Programa foi executado por dois órgãos separadamente, CAPES e CNPq, cada um com sua forma de gestão. Após sua instituição oficial (13 de dezembro de 2011), a execução passou a ser conjunta, por meio de representaçóes nos comitês criados.

$\mathrm{Na} 2^{\mathrm{a}}$ convocação (dezembro de 2011), percebe-se que a administração federal do CsF, após oficialmente criado, assumiu completamente a sua gestão, limitando a atribuição das IES brasileiras à homologação de elegibilidade dos candidatos. 
Nesse escopo, ampliou o público-alvo por meio da alteração de matriculados em curso de bacharelado para curso de nível superior e também pela aceitação de outras modalidades de proficiência linguística, além de esclarecer dúvidas acerca das áreas contempladas e oportunizar cursos intensivos de idioma no exterior.

$\mathrm{Na}$ passagem da $1^{\mathrm{a}}$ convocação (agosto de 2011) para a $2^{\mathrm{a}}$, destaca-se a redução da participação das instituições de ensino superior no processo de escolha do bolsista. No primeiro momento, a IES tinha a responsabilidade pela organização e acompanhamento do processo de apresentação das candidaturas e pela respectiva homologação na CAPES, o que sofre alteração. Ao que parece, o Programa preserva a gestão estatal para não sofrer interferências na sua matriz estrutural.

Identifica-se na $3^{\text {a }}$ convocação (março de 2012) que o CsF, buscando ampliar o público-alvo, alterou consideravelmente o requisito do período de integralizaçáo do curso. Ao transferir de $40 \%-80 \%$ para $20 \%-90 \%$ passam a serem elegíveis os estudantes que cursam o seu primeiro semestre de estudos; assim, dependendo do seu tempo total de curso, teráo integralizado até o início da viagem, setembro de 2012, o mínimo exigido. Ao mesmo tempo, os estudantes que estão próximos à finalização do curso também poderão concluir seus estudos no exterior, retornando ao Brasil apenas para colação de grau. Outra medida adotada foi excluir o requisito de apresentação de comprovantes da nota do Programa Universidade para Todos (Prouni) ou do Sistema de Seleção Unificada (SiSU) com nota no Exame Nacional do Ensino Médio (ENEM) igual ou superior a 600 pontos para as candidaturas individuais.

Além disso, persistiam os desencontros acerca das áreas e temas prioritários de atuação contemplados pelo Programa. Tal fato levou o Ministério da Educação a publicar, em 9 de janeiro de 2013, a Portaria Interministerial n.1, que delimitou as prioridades.

Até então, ou, mais exatamente, nas $1^{\mathrm{a}}, 2^{\mathrm{a}}$ e $3^{\mathrm{a}}$ convocações, as formas de participação no CsF eram duas: por meio das IES brasileiras que fizessem adesão ao Programa e mediante candidatura individual destinada a estudantes das IES brasileiras que não aderiram ao Programa. Porém, na $4^{\text {a }}$ convocação (agosto de 2012), a modalidade de candidatura individual foi extinta.

Destaca-se na modalidade de participaçáo por adesão das IES brasileiras a obrigatoriedade da candidatura individual apresentar comprovantes dos Prêmios Jovem Cientista, Iniciação Científica e Olimpíadas da Matemática e/ou de Ciências.

Depois da primeira experiência do Programa em enviar estudantes para a Espanha sem exigir o teste de proficiência linguístico foi necessário estabelecer o referido teste, visando melhor desempenho acadêmico e convivência social dos bolsistas, obrigatoriedade incluída na $5^{\text {a }}$ convocaçâo (novembro de 2012). 
Por sua vez, ainda com problemas de interpretação dos cursos elegíveis das áreas e temas, foi anexada em todas as Chamadas da $5^{\text {a }}$ convocação uma lista dos cursos elegíveis e acrescentados dois subitens que limitavam a participação dos estudantes das áreas de Ciências Biológicas e Saúde no ciclo clínico, ou seja, nas atividades práticas de cursos como Medicina, Enfermagem, Farmácia, entre outros. Além disso, foi limitada a participação dos estudantes das áreas de Comunicação Social, que eram alocados na área Indústria Criativa. Nota-se que, mesmo depois da publicação da Portaria do Ministério da Educação que instituiu as áreas e cursos de atuação do Programa, persistiam as dúvidas acerca da área elegível.

Há de registrar, ainda, a criação dos dispositivos Recursos Financeiros, Recursos Administrativos e Impugnação da Chamada, visando proteger o Programa de possíveis ações judiciais.

É igualmente importante evidenciar que somente a Chamada Pública 128 França (novembro de 2012) ofereceu curso intensivo de idioma aos candidatos escolhidos pelo Programa.

$\mathrm{Na} 6^{\mathrm{a}}$ convocação (fevereiro de 2013) tem-se a definição de que cabe a CAPES e ao $\mathrm{CNPq}$ estabelecer a elegibilidade da candidatura com relação às diversas áreas e temas, bem como sobre as atribuiçóes das IES e do Programa CsF quanto a sua operacionalização. Ambas as decisôes, dadas somente após um ano e meio de execução do CsF, demonstram a forma imprecisa de sua construçáo.

Resumidamente, da $1^{\text {a à }} 6^{\text {a }}$ convocação, é possível observar que o Programa foi sendo alterado no sentido de adaptar-se às dificuldades encontradas, seja em relação ao período de integralização do curso que o candidato deve situar-se para sua participação, seja em relação ao curso de idiomas ou na definição dos cursos elegíveis. Sinalizam-se, pois, alterações com o objetivo de obter sucesso na meta estabelecida:

O projeto prevê a utilização de até 101 mil bolsas em quatro anos para promover intercâmbio, de forma que estudantes de graduação e pós-graduação façam estágio no exterior com a finalidade de manter contato com sistemas educacionais competitivos em relação à tecnologia e inovação. (CsF, 2011g).

Posteriormente, na $7^{a}$ convocação (maio de 2013), destaca-se a relação com outra política de acesso por meio do requisito de nota do ENEM, utilizado como prova para ingresso em diversas instituiçóes de ensino superior no Brasil.

$\mathrm{Na}$ definição da $8^{\mathrm{a}}$ convocação (outubro de 2013), chama atenção a ênfase para que os candidatos se inscrevam no processo seletivo interno das IES de 
origem. Provavelmente, isso se relacionou à manifestação das IES nas reunióes de Coordenadores Institucionais do Programa CsF, requerendo autonomia institucional. Em outras palavras, significava o pleito de atendimento prioritário às regras próprias das IES, que são deliberadas por seus órgãos colegiados.

Um exame comparativo das informaçóes constantes na $6^{\mathrm{a}}, 7^{\mathrm{a}}$ e $8^{\mathrm{a}}$ convocaçóes permite inferir que o Programa CsF foi reagindo às demandas da sociedade, reconhecendo a necessidade de adaptaçóes por meio de açóes, desde centralizar a gestão nos órgãos CAPES/CNPq até a parceria com o curso de inglês online My English On Line (MEO) para ensino do idioma inglês. No mesmo sentido, posteriormente, a adaptação veio pela criação do Inglês sem Fronteiras. Observa-se, ainda, adequaçôes como a publicação oficial sobre quem define áreas prioritárias, a implementação de dispositivos de segurança jurídica, o veto a Portugal, a ênfase na última convocatória sobre a obrigatoriedade do estudante se inscrever no processo seletivo interno das IES, entre outras.

É notório que o CsF preserva a gestão estatal, com reduzida participação das IES brasileiras, provavelmente, para não sofrer interferências na sua matriz estrutural. Porém, a centralizaçáo dá sinais de contrariar um dos objetivos divulgados em seu documento de criação: “[...] IV. Estimular iniciativas de internacionalização das universidades brasileiras [...]" (DECRETO n. 7.642, de 13 de dezembro de 2011). Essa pode ser vista como uma das contradiçóes identificadas no Programa CsF.

Ainda sobre as convocaçóes relativas ao CsF, em agosto de 2014, foi lançada a $9^{a}$ convocação, após dez meses da anterior. Nela, destaca-se a limitação ou exclusão total de alguns cursos das áreas da Saúde, Ciências Biológicas e Indústria Criativa, notadamente Medicina, por alegação de incompatibilidade curricular. Outro destaque nessa convocação, no âmbito do que era gerido pela CAPES, refere-se às vagas por países. De um total de 8.550 vagas, o país de destino com maior número é EUA, com 5.600, seguindo-se: Alemanha, 500; França, 500; Itália: 500; Suécia, 100; Noruega, 100; China, 100; Hungria, 300, Japão, 100; Áustria, 50; Canadá, 200; e Irlanda, 500.

Em suma, entende-se que o desenvolvimento do Programa CsF prima por certos traços:

- Meritocracia. Existe um sistema de classificação pautado em pontuação acrescida para candidatos contemplados por prêmios acadêmicos e de mérito, sendo eles: Prêmios Jovem Cientista, Iniciação Científica e Olimpíadas de Matemática e/ou de Ciências e demais premiaçóes de mérito acadêmico. A pontuação é também acrescida para candidatos que tenham participação em programas de iniciação científica, tecnológica ou 
docência e para os que já possuam domínio linguístico em outro idioma. Além disso, leve-se em conta o corte de elegibilidade pela nota no ENEM igual ou superior a 600 pontos, incluído a partir da $7^{\mathrm{a}}$ convocaçáo;

- Vertente científico-tecnológica. As áreas e temas, apesar das constantes alterações, mantiveram seu foco em cursos determinados, com intuito de suprir a necessidade de mão de obra técnica qualificada, visando empresas como Vale, Petrobras e Eletrobras ${ }^{6}$;

- Parceria com países desenvolvidos. As Chamadas Públicas visavam maciçamente países da América do Norte e Europa, com destaque para Canadá e Estados Unidos da América, que, juntos, somavam 21\% do total de Chamadas ofertadas;

- Parceria público-privada. Tanto IES públicas quanto IES privadas nacionais podem enviar bolsistas para as públicas ou privadas no exterior, e vice-versa, garantindo-se o repasse público para pagamento das taxas acadêmicas privadas. Outrossim, identifica-se o interesse de empresas fomentarem bolsas com o objetivo de que os intercambistas, ao voltarem ao Brasil, sejam incorporados ao setor produtivo, na sua área de formação.

Por fim, um traço fundamental do CsF, tendo em vista o foco do presente estudo, refere-se ao pagamento de taxas acadêmicas às instituiçóes de destino estrangeiras por parte do Estado brasileiro, configurando a modalidade transnacional consumo no estrangeiro, citada por Santos (2011, p.34):

[...] consiste na provisão do serviço através do movimento transnacional do consumidor. É esta atualmente a grande fatia da transnacionalização mercantil da universidade. Um estudo recente da OCDE calcula que este comércio valia, em 1999, 30 bilhốes de dólares. No início de 2000, 514 mil estrangeiros estudavam nos EUA, mais de $54 \%$ oriundos da Ásia. (SANTOS, 2011, p. 34).

Para ilustrar, o Quadro 2 demonstra os valores iniciais negociados entre o Programa CsF e os parceiros internacionais, em novembro de 2011, às vésperas do lançamento das chamadas da $2^{\text {a }}$ convocação.

6 Essas são empresas que possuem acordo firmado com o Programa CsF. Trata-se de "empresas financiadoras atuam em conjunto com o CNPq e a CAPES, com a finalidade de apoiar e complementar o Programa Ciência sem Fronteiras [...]” (BRASIL/CsF, 2011d). 
Quadro 2 - Custo por bolsista/ano do Programa CsF

\begin{tabular}{|l|c|c|}
\hline País & Valor/ Ano/ por Bolsista CsF & Referência \\
\hline EUA & US\$35.950 & Taxas escolares + Acomodação \\
\hline Reino Unido & $£ 15.000$ & $\begin{array}{c}\text { Taxas escolares + Acomodação + Curso de } \\
\text { Idioma }\end{array}$ \\
\hline Alemanha & $€ 2.500$ & Taxas administrativas + Curso de Idioma \\
\hline Itália & $€ 2.500$ & Taxas administrativas + Curso de Idioma \\
\hline
\end{tabular}

Fonte: Dados organizados pelas autoras, com base na apresentação "CsF: Um programa especial de mobilidade internacional em ciência, tecnologia e inovação", (CNPq, nov. 2011).

Portanto, fica evidente que o citado Programa mobiliza o fator mercadológico no seu funcionamento. Agregando-se a outras características que lhe são peculiares, esse traço sinaliza um retraimento dos intercâmbios pautados em cooperaçáo e trocas acadêmicas solidárias.

Outro aspecto a ser considerado refere-se ao silêncio acerca da responsabilidade social do estudante que retorna ao país de origem, após usufruir um benefício custeado pelo Estado. É possível especular que tal questão traga subjacente a ideia de individualidade sobre a de bem coletivo, na medida em que não se estabelece um compromisso na direção da retribuição social.

\section{Considerações finais}

A pesquisa apresentada procurou entender como se expressa o Programa CsF, levando em conta os princípios fundamentais da internacionalização e da transnacionalização da educação superior.

Ao que se apurou, o Programa articula-se à presente fase do sistema capitalista no país, que clama por recursos humanos qualificados para enfrentar as necessidades próprias do crescimento econômico, no chamado mundo globalizado. Isso se expressa pela intencionalidade de formação nas áreas de ciência, tecnologia e inovação, o que seria estratégico para o país, na medida em que promove a competitividade empresarial nacional e o projeta como potência econômica.

Numa leitura questionadora da realidade em foco, entende-se que não se sustenta o discurso de redenção social via conhecimento e promessa de conduzir a sociedade a um tempo de prosperidade, se o Estado omitir reformas sociais abrangentes, a exemplo de uma efetiva distribuição de renda. No que tange à 
educação, reformas abrangentes implicariam, por exemplo, no pleno acesso à educação superior em instituiçóes formadoras, reconhecidas e inspiradas na inserçáo social ou na atenção a problemas que se relacionam ao bem-estar coletivo.

A propósito, Silva (2008), resgatando Barros (2002), no debate sobre a produção do conhecimento, aponta que em 1995 Estados Unidos, Japáo e Europa detinham $74,8 \%$ da produçáo científica mundial, evidenciando a correlação entre capacidade de pesquisa e poder econômico.

Essa análise traz à tona a característica do Programa CsF concernente à parceria com países desenvolvidos, principalmente os Estados Unidos da América, que receberam aproximadamente $30 \%$ dos bolsistas. Logo, há de destacar o asseverado por Altbach (2001, p. 71 apud DIAS SOBRINHO, 2005, p. 84, grifo do autor): "As nações do Terceiro Mundo são basicamente 'consumidoras' de conhecimento, dependentes das naçóes industrializadas no que respeita à investigação, às interpretaçóes dos avanços científicos e, em geral, à informação."

Posto que o CsF foi concebido com vistas a buscar (e referenciar-se) no conhecimento produzido fora do país, admite-se que o Brasil se apresenta na condição de consumidor de conhecimento, ou seja, paga por uma mercadoria posta à venda pelo mercado educacional produzido no exterior.

Em face dessas análises, uma das contradiçôes básicas incide na utilização do termo internacionalização por parte do Programa analisado, que expressa, na verdade, a compra e a venda do produto conhecimento qualificado. Em outras palavras, revela-se nisso a transnacionalização da educação superior.

Interpreta-se, portanto, que, em essência, a internacionalização da educação superior oculta a sua transnacionalização. Isso vem no sentido advertido por De Wit (2002, p.114 apud MUELLER, 2013, p. 25) sobre o uso do termo internacionalização da educação superior, que detém interesses e uma estrutura conceitual que o acompanha e se mostra relevante:

[...] à medida que a dimensão internacional da educação superior ganha mais atenção e reconhecimento, as pessoas tendem a usar o termo da forma que melhor satisfaça aos seus propósitos. Uma definição mais focada é necessária para ser entendida com a importância que ela merece. Mesmo se não houver concordância sobre a definição, a internacionalização precisa ter parâmetros para ser avaliada e, portanto, contribuir com a educaçáo superior. Este é o motivo pelo qual o uso de uma definição em construção com uma estrutura conceitual é relevante para internacionalização do ensino superior. (DE WIT 2002, p.114 apud MUELLER, 2013, p. 25). 
Vale reiterar que a internacionalização da educação superior tem como elemento norteador o valor universal do conhecimento, nutrindo-se da troca mútua e solidária. Ou seja, existe uma mão dupla, traduzida pela busca de soluçóes para questóes humanitárias, que podem ser a fome, doenças, sustentabilidade, violência, etc., ou mesmo a busca por soluçóes de problemas locais/regionais, que venha a ser compartilhada por sociedades diversas.

Acredita-se que a experiência da cooperação internacional, potencialmente, desenvolva habilidades interculturais, ampliação das vertentes do conhecimento acadêmico, visão holística do saber e, inclusive, promoção do bem-estar social. Ou seja, a educaçáo desenvolvida pode repercutir nos indivíduos participantes de certa modalidade da internacionalização (intercâmbio, pesquisas conjuntas, entre outras experiências), bem como nas instituiçóes de educação superior propriamente e em setores populacionais implicados no processo.

$\mathrm{Na}$ outra ponta, a transnacionalização, ao exprimir uma relação mercantil (completada por atributos como: utilitarismo, pragmatismo, lucro, verticalidade, domínio/subalternidade, individualidade), tende a priorizar interesses privados, em detrimento da noção de diálogo e interesse coletivo.

Nos limites do que foi estudado e nos contornos do tempo histórico a que se refere, conclui-se que a concepção e a implementação do CsF expressa, em boa parte, fundamentos da transnacionalizaçáo. A partir disso, indaga-se se o referido Programa, por sua visibilidade, centralidade e aporte de recursos, estaria se constituindo no eixo estruturante da política de internacionalizaçáo da educação superior no Brasil, difundindo princípios e procedimentos.

\section{Referências}

BRASIL. Ministério da Ciência Tecnologia e Inovação. País terá R\$ 3,16 bi para formar cientistas, Brasília, DF, 27 jul. 2011a. Disponível em: <http://www. cienciasemfronteiras.gov.br/web/noticiais>. Acesso em: 14 jun. 2013.

BRASIL. Ministério da Ciência Tecnologia e Inovação; Ministério da Educação. Programa Ciência sem Fronteiras. Chamadas Públicas: CNPq e n. ${ }^{\circ} 102$ a no 204, Brasília, DF, 2011b. Disponível em: <http://www.cienciasemfronteiras.gov. br/web/csf/inscricoes-resultados>. Acesso em: 5 set. 2014.

BRASIL. Ministério da Educação. Aviso de Chamada Pública n. 1/2011, de 29 de agosto de 2011. Programa Ciência sem Fronteiras - Graduação sanduíche nos EUA. Diário Oficial da Uniáo, Brasília, DF, 29 ago. 2011c Seção 3, p. 27. Disponível em: <http://pesquisa.in.gov.br/imprensa/jsp/visualiza/index.jsp?data=29/08/2011 \&jornal=3\&pagina=27\&totalArquivos=176>. Acesso em: 15 mar. 2014. 
BRASIL. Ministério da Educação. Capes e CNPq realizam reuniáo com coordenadores do CsF, Brasília, DF, 7 out. 2014a. Disponível em: <http:// www.capes.gov.br/sala-de-imprensa/noticias/7192-capes-e-cnpq-realizamreuniao-com-coordenadores-do-programa-ciencia-sem-fronteiras $>$ Acesso em: 25 fev. 2015 .

BRASIL. Ministério da Educação. Empresas financiadoras, 2011d. Brasília, DF. Disponível em: <http://www.cienciasemfronteiras.gov.br/web/csf/sobre>. Acesso em: 6 abr. 2014.

BRASIL. Ministério da Educação. Instituiçóes de Destino, Brasília, DF, 2011e. Disponível em: <http://www.cienciasemfronteiras.gov.br/web/csf/instituicoesde-destino1>. Acesso em: 9 abr. 2014.

BRASIL. Ministério da Educação. Mercadante lança o Programa Ciência Sem Fronteiras, Brasília, DF, 27 jul. 2011f. Disponível em: <http://www. cienciasemfronteiras.gov.br/web/noticiais>. Acesso em: 14 jun. 2013.

BRASIL. Ministério da Educação. O Programa, 2011g. Brasília, DF. Disponível em: < http:/www.cienciasemfronteiras.gov.br/web/csf/o-programa>. Acesso em: 6 abr. 2014.

BRASIL. Ministério da Educação. Portaria Interministerial n. 1, de 9 de janeiro de 2013. Institui as áreas e temas prioritários para o Programa Ciência sem Fronteiras. Diário Oficial da Uniáo, Brasília, DF, 11 jan. 2013. Seção 1, p. 24. Disponível em: <http://www.cienciasemfronteiras.gov.br/documents/214072/0/ MEC_MCTI_institui+\%C3\%A1reas+e+temas+priorit\%C3\%A1rios_ Ci\%C3\%AAncia+sem+Fronteiras.pdf> Acesso em: 25 maio 2013.

BRASIL. Presidência da República. Constituiçáo da República Federativa do Brasil de 1988, Brasília, DF, 1988. Disponível em: <http://www.planalto.gov. br/ccivil_03/constituicao/constituicaocompilado.htm>. Acesso em: 25 set. 2014

BRASIL. Presidência da República. Decreto n. 7642, de 13 dez. 2011h. Institui o Programa Ciência sem Fronteiras. Disponível em: <http://www.planalto.gov.br/ ccivil_03/_Ato2011-2014/2011/Decreto/D7642.htm>. Acesso em: 25 maio 2013.

BRASIL. Presidência da República. Discurso da Presidenta da República, Dilma Rousseff, na cerimônia de regulamentaçáo do programa Ciência sem Fronteiras e de anúncio de chamadas públicas para bolsas de estudo no exterior, 2011i, Brasilia, DF. Disponível em: <http:/wwww2.planalto.gov.br/acompanhe-o-planalto/discursos/discursosda-presidenta/discurso-da-presidenta-da-republica-dilma-rousseff-na-cerimonia-deregulamentacao-do-programa-ciencia-sem-fronteiras-e-de-anuncio-de-chamadas-publicaspara-bolsas-de-estudo-no-exterior-brasilia-df . Acesso em: 23 fev. 2015. 
BRASIL. Presidência da República. Casa Civil. Subchefia para Assuntos Jurídicos. Lei no 9.394, de 20 de dezembro de 1996. Estabelece as diretrizes e bases da educaçáo nacional. Brasília, DF, DOU, 23 dez. 1996. Disponível em: <http:// www.planalto.gov.br/ccivil_03/Leis/L9394.htm>. Acesso em: 25 set. 2014.

BRASIL. Presidência da República. Lei n. 13005, de 25 jun. 2014. Aprova o Plano Nacional de Educaçáo. Brasília, DF, 2014b. Disponível em: <http://www.planalto. gov.br/ccivil_03/_Ato2011-2014/2014/Lei/L13005.htm>. Acesso em: 25 set. 2014.

CADE autoriza união de Anhanguera e Kroton, com ressalvas. Folha de Sáo Paulo, São Paulo, 15 mai. 2014. Disponível em: <http://www1.folha.uol.com. $\mathrm{br} / \mathrm{fsp} / \mathrm{mercado} / 165944$-cade-autoriza-uniao-de-anhanguera-e-kroton-comressalva.shtml>. Acesso em: 2 fev. 2015.

CARVALHO, Cristina Helena Almeida de. A mercantilização da educação superior brasileira e as estratégias de mercado das instituiçóes lucrativas. Revista Brasileira de Educação, Rio de Janeiro, v. 18, n. 54, 2013.

CATANI, Afrânio Mendes; SILVA JÚNIOR, João dos Reis. A educação superior pública brasileira nas duas últimas décadas: expansão e mercantilização internacionalizada. In: SOUSA, José Vieira de (Org.). Educação superior: cenários, impasses e propostas. Campinas: Autores Associados, 2013.

CHARLE, Chistophe; VERGER, Jacques. História das Universidades. São Paulo: Editora da Universidade Estadual Paulista, 1996.

DIAS, Marco Antonio Rodrigues. Educação superior: bem público ou serviço comercial regulamentado pela OMC? In: PANIZZI, Wrana Maria. Universidade: um lugar fora do poder. Porto Alegre: UFRGS Editora, 2002.

DIAS SOBRINHO, José. Dilemas da educação superior no mundo globalizado. Sociedade do conhecimento ou economia do conhecimento. São Paulo: Casa do Psicólogo, 2005.

HARVEY, David. Condição pós-moderna. São Paulo: Loyola, 1989.

MOROSINI, Marília Costa. Internacionalização da Educação Superior no Brasil pós-LDB: o impacto das sociedades tecnologicamente avançadas. In: BITTAR, Mariluce et al. (Org.). Educaçáo superior no Brasil: 10 anos pós-LDB. Brasília, DF: INEP, 2008. (Coleção Inep 70 anos, v. 2).

MUELLER, Cristiana Verônica. O processo de internacionalizaçáo do ensino superior: um estudo de caso da Universidade Federal do Rio Grande do Sul. 2013. 178 f. Dissertação (Mestrado em Relaçôes Internacionais)- Instituto de Filosofia e Ciências Humanas, Universidade Federal do Rio Grande do Sul, Porto Alegre, 2013. 
PENA, Rodolfo Alves. Terceira Revolução Industrial. Brasil Escola, 2015. Disponível em: <http://www.brasilescola.com/geografia/terceira-revolucaoindustrial.htm>. Acesso em: 7 jan. 2015.

QS World University Rankings, EUA. Disponível em:<http://www.topuniversities. $\mathrm{com} /$ university-rankings/world-university-rankings/2013\#sorting=rank+region= + country $=+$ faculty $=+$ stars $=$ false+search=>. Acesso em: 31 mar. 2014.

SANTOS, Boaventura de Sousa. A universidade no século XXI: para uma reforma democrática e emancipatória da Universidade. São Paulo: Cortez, 2011.

SILVA, Maria das Graças Martins da. Trabalho docente na Pós-Graduaçáo: a lógica da produtividade em questáo. 2008. 234 f. Tese (Doutorado em Educação)Universidade Federal do Rio Grande do Sul, Porto Alegre, 2008.

THE World Reputation Rankings, Londres. Disponível em: <http://www. timeshighereducation.co.uk/world-university-rankings/2014/reputationranking>. Acesso em: 31 mar. 2014. 